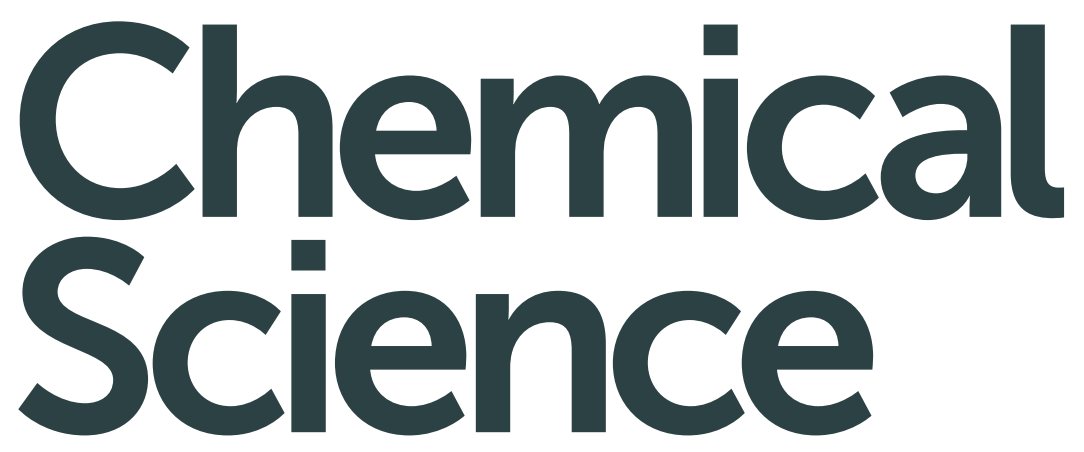

rsc.li/chemical-science
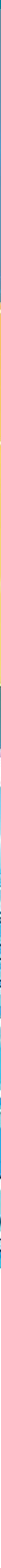
Check for updates

Cite this: Chem. Sci., 2018, 9, 6749

๑ All publication charges for this article have been paid for by the Royal Society of Chemistry

Received 4th June 2018

Accepted 30th June 2018

DOI: $10.1039 / c 8 s c 02446 d$

rsc.li/chemical-science

\section{A redox-activated theranostic nanoagent: toward multi-mode imaging guided chemo-photothermal therapy $\dagger$}

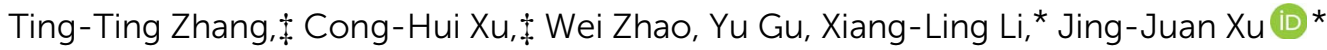 \\ and Hong-Yuan Chen
}

Development of tumor microenvironment responsive and modulating theranostic nano-systems is of great importance for specific and efficient cancer therapy. Herein, we report a redox-sensitive nanoagent combining manganese dioxide $\left(\mathrm{MnO}_{2}\right)$ and gold nanoshell coated silicon nanoparticles for synergistic chemo-photothermal therapy of hypoxia solid tumors. In highly reducing tumor tissues, the outer $\mathrm{MnO}_{2}$ nanosheet with the loaded drug would be dissociated by intracellular glutathione (GSH), resulting in ondemand drug release, as well as generating $\mathrm{Mn}^{2+}$ ions which provided high contrast magnetic resonance imaging (MRI), and fluorescence imaging (FI) in vitro and in vivo. While upon near-infrared (NIR) light irradiation, the gold nanoshell modulated the hypoxic tumor microenvironment via increasing blood flow, achieving enhanced photothermal therapy (PTT) and chemotherapy. After tail vein injection into tumor-bearing mice and monitoring in real time, the intelligent redox-activated nanoagent exhibited high tumor accumulation and powerful synergistic chemo-photothermal therapy efficiency. The proposed work developed a noninvasive strategy to modulate the tumor microenvironment and enhance the anticancer therapeutic effect. We believe that this single nano-platform exhibits promising potential as a comprehensive theranostic agent to enhance the efficacies of synergistic cancer therapy.

\section{Introduction}

The microenvironments in healthy tissues are strictly regulated and closely correlated with the physiological state of the cell. However, in tumor tissues, the regulation is disrupted with abnormal features such as low $\mathrm{pH}$ values, hypoxia and high lactate levels. ${ }^{1}$ Among the unique features of the tumor microenvironment, the redox status is a prominent and important parameter, since it could determine the response of a tumor to both radiation and chemotherapies. ${ }^{2,3}$ For instance, the substantial presence of intracellular glutathione (GSH) would significantly decrease the effective production of reactive oxygen species (ROS) and weaken the therapeutic effect. ${ }^{4}$ However hypoxia, another hallmark property of solid tumors, ${ }^{5}$ which is related to metastatic progression and highly detrimental to disease theranostics, ${ }^{6-8}$ leads to the hypoxia-associated resistance of the tumor tissues and significantly limits the therapeutic efficiency. ${ }^{9}$ Therefore, designing a tumor microenvironment responsive multifunctional nanomaterial which

State Key Laboratory of Analytical Chemistry for Life Science, Collaborative Innovation Center of Chemistry for Life Sciences, School of Chemistry and Chemical Engineering, Nanjing University, Nanjing 210023, China.E-mail:xlli@nju.edu.cn; xujj@nju.edu.cn † Electronic supplementary information (ESI) available. See DOI: 10.1039/c8sc02446d

\$ These authors contributed equally to the work. could reflect the redox status and even modulate the microenvironment shows promising potential to not only realize specific cancer treatment, but also greatly enhance the therapeutic effect.

In recent years, efforts have been devoted to the development of nanomaterials as therapeutic agents which took effect in response to the tumor environment, especially acidic $\mathrm{pH}$ and intracellular redox potential. ${ }^{\mathbf{1 0 - 1 5}}$ Plenty of nanostructures, including micelles, nanogels, macromolecular conjugates, nano-sized nucleic acid complexes and metallic nanoparticles have been constructed for controlled cancer treatment. ${ }^{\mathbf{1 6 - 2 0}}$ Among the various nanoagents, $\mathrm{MnO}_{2}$ nanostructures have attracted substantial attention as a unique type of $\mathrm{H}^{+}$and $\mathrm{GSH}$ responsive mediator for drug release and redox imaging. ${ }^{21-23}$ It has been found that $\mathrm{MnO}_{2}$ could be decomposed in cancer cells, generating $\mathrm{Mn}^{2+}$ ions that are able to significantly enhance magnetic resonance imaging (MRI) contrast for tumor status imaging. ${ }^{24}$ Meanwhile, the harmless water-soluble $\mathrm{Mn}^{2+}$ ions can be rapidly excreted by kidneys with no long-term toxicity concerns for in vivo applications. ${ }^{25}$ However, as the tumor cells proliferated rapidly, the hypoxia environment is still one of the critical obstacles for both chemotherapy and radiotherapy. To pursue better therapeutic effect, the photothermal therapy (PTT), with inherent merits - minimal invasiveness, increased treatment accuracy, and reduced damage to normal tissues has been applied in synergistic treatment of tumors. ${ }^{26-30}$ As mild 
hyperthermia generated by PTT via absorbing light in the near infrared region (NIR) can accelerate the blood flow in solid tumors, it could improve the oxygenation level and alleviate the hypoxia-associated therapeutic resistance. ${ }^{31,32}$ The synergistic chemotherapy/PTT approach can conquer the hypoxia-associated resistance existing in tumor issues and enhance the therapeutic efficacy in a synergistic manner. ${ }^{33}$ However concomitant noninvasive imaging techniques, including photothermal imaging, fluorescence imaging (FI) and MRI, facilitated monitoring the therapeutic process, especially chemotherapeutic progress in real time, which was beneficial for guiding cancer treatment more efficiently. ${ }^{34-37}$ Although pioneering studies have been reported on the synergistic treatment and noninvasive imaging, it is still challenging and critical to develop a highly efficient nano-scale theranostic system with multiple functions in one nanoagent.

Herein, we have designed and fabricated a theranostic nanoagent ( $\left.\mathrm{SiO}_{2} @ \mathrm{Au} @ \mathrm{MnO}_{2}-\mathrm{DOX} / \mathrm{Apt}\right)$ via a photothermal nanomaterial, $\mathrm{SiO}_{2} @$ gold shell, coupled with a two-dimensional (2D) $\mathrm{MnO}_{2}$ nanosheet as a carrier for the chemotherapeutic drug, doxorubicin hydrochloride (DOX). The nanoagent could be triggered by the inherent redox features of the tumors, and attack the hypoxic solid tumors without damaging normal tissues. As systematically illustrated in Scheme 1, after the aptamer modified nanoagent recognized and entered the specific tumor cell, the $\mathrm{MnO}_{2}$ nanosheet was rapidly reduced by overexpressed GSH in the cytoplasm, producing a large amount of free $\mathrm{Mn}^{2+}$ ions for MRI, as well as releasing DOX and inducing the recovery of fluorescence. Meanwhile, under NIR irradiation, the retained $\mathrm{SiO}_{2} @$ gold shell structure accelerated the blood flow in the solid tumor, which alleviated the hypoxic microenvironment and improved the photothermal treatment.

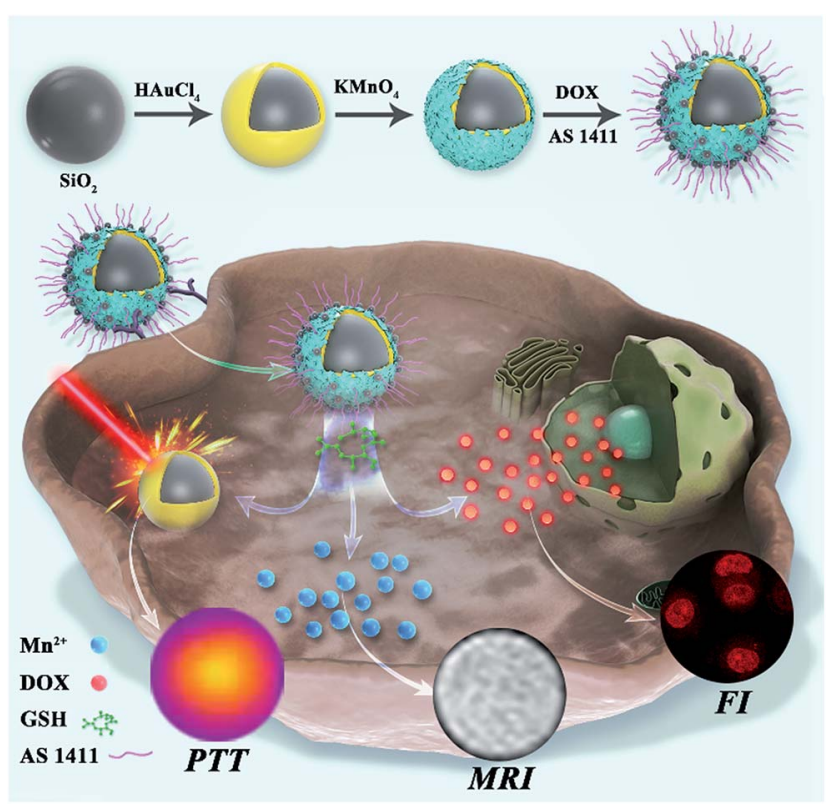

Scheme 1 Schematic illustration of the synthetic process, in situ imaging and the therapeutic mechanism of the nanoagent $\mathrm{SiO}_{2} \mathrm{a}-$ Au@ $\mathrm{MnO}_{2}-\mathrm{DOX} /$ Apt.
The proposed nanoagent integrated synergistic chemo-photothermal therapy with multiple imaging techniques (photothermal imaging/FI/MRI) into a single platform, providing an all-in-one solution. During the in vivo study, the formulated nanoagent was monitored to be accumulating in the tumor after tail vein injection into HeLa tumor-bearing mice, which greatly inhibited the growth of the tumor with no damage or inflammatory lesion in major organs. On the basis of its high therapeutic efficiency and noninvasive multiple monitoring modes, this multifunctional redox-activated nanoagent holds great potential in the precise treatment of cancer.

\section{Results and discussion}

\section{Characterization of $\mathrm{SiO}_{2} @ \mathrm{Au} @ \mathrm{MnO}_{2} \mathrm{NPs}$}

The synthesis procedure of $\mathrm{SiO}_{2} @ \mathrm{Au} @ \mathrm{MnO}_{2}$ core-shell nanoparticles is illustrated in Scheme 1. Firstly, the core $\mathrm{SiO}_{2}-\mathrm{NH}_{2}$ nanoparticles were synthesized by a reported Stöber method. ${ }^{38}$ Transmission electron microscopy (TEM) images revealed that the synthesized $\mathrm{SiO}_{2}-\mathrm{NH}_{2}$ was smooth and spherical with a uniform diameter of $\sim 110 \mathrm{~nm}$ (Fig. 1a). Secondly, the interlayer gold shell as an efficient photothermal nanomaterial grew on the $\mathrm{SiO}_{2}$ core via a seed-growth procedure in two steps. ${ }^{39} \mathrm{On}$ reduction using sodium borohydride, small $\mathrm{Au}$ nanoparticles with a diameter of $\sim 5 \mathrm{~nm}$ were generated on the surface of the $\mathrm{SiO}_{2}-\mathrm{NH}_{2}$ nanospheres (Fig. 1b). Then, on subsequent reduction using hydroxylammonium chloride, a gold nanoshell was formed at the outside of $\mathrm{SiO}_{2}$, which exhibited a nearly spherical morphology with a large diameter of $\sim 180 \mathrm{~nm}$ (Fig. 1c). Thirdly, the outer layer $\mathrm{MnO}_{2}$ nanosheet as both a fluorescence quencher and a drug carrier is coated on $\mathrm{SiO}_{2}$ @gold shell via electrostatic interaction. ${ }^{23}$ As concepts described, TEM observations showed rough surface $\mathrm{MnO}_{2}$ nanomaterials as the outer layer around $\mathrm{SiO}_{2} @$ @old shell, and the $\mathrm{MnO}_{2}$ layer was clearly observed in the high-resolution TEM (HRTEM) image (Fig. 1d). Elemental distribution mappings by high-angle annular darkfield scanning TEM (HAADF-STEM) and energy dispersive spectroscopy (EDS) were performed to further investigate the core-shell structure. As shown in Fig. 1e-h, elemental distribution mappings of $\mathrm{Au}, \mathrm{Mn}$ and $\mathrm{O}$ elements validated the

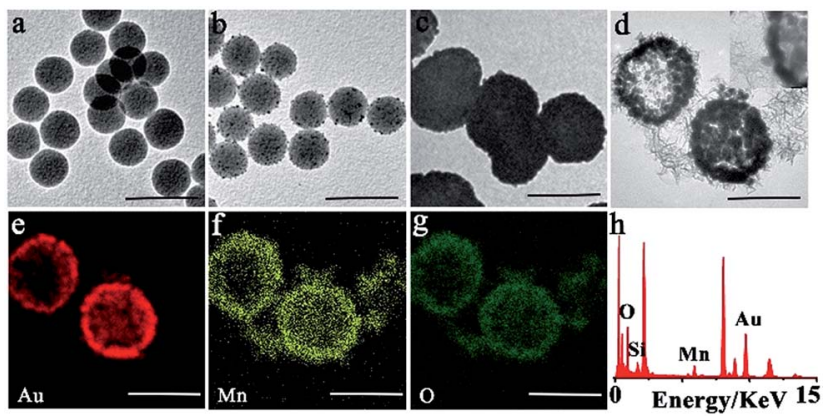

Fig. 1 (a)-(d) TEM of $\mathrm{SiO}_{2}-\mathrm{NH}_{2}, \mathrm{SiO}_{2}$ agold seed, $\mathrm{SiO}_{2}$ agold shell and $\mathrm{SiO}_{2}\left(\mathrm{Au} @ \mathrm{MnO}_{2}\right.$. Inset: the HR-TEM of $\mathrm{SiO}_{2} \mathrm{aAu}\left(\mathrm{MnO}_{2}\right.$. (e)-(g) The corresponding elemental mappings of $\mathrm{SiO}_{2}\left(\mathrm{aAu} \mathrm{aMnO}_{2}\right.$ (e) $\mathrm{Au}$, (f) $\mathrm{Mn}$, (g) $\mathrm{O},(\mathrm{h})$ the energy dispersive spectrum of $\mathrm{SiO}_{2}\left(\mathrm{aAu}\left(\mathrm{MnO}_{2}\right.\right.$. Scale bar: $200 \mathrm{~nm}$. 
coexistence of the nanomaterials and the core-shell nanostructure. The EDS also demonstrated the coexistence of the Si, $\mathrm{Au}, \mathrm{Mn}$ and $\mathrm{O}$ elements and further illustrated the successful fabrication of $\mathrm{SiO}_{2} @ \mathrm{Au} @ \mathrm{MnO}_{2}$. The layer by layer coating process was also verified by zeta potential analysis and UV-visNIR absorbance measurements (Fig. S1a and $\mathrm{b}_{\dagger}^{\dagger}$ ). During the synthetic process, the zeta potential ( $\zeta)$ showed a positive potential of approximately $6.1 \mathrm{mV}$ for the core $\mathrm{SiO}_{2}-\mathrm{NH}_{2}$, and a negative potential of $-11.3 \mathrm{mV}$ for $\mathrm{SiO}_{2}$ @gold shell. After formation of $\mathrm{MnO}_{2}$ nanosheets, it was negatively shifted to $-17.6 \mathrm{mV}$. UV-vis-NIR spectra of both $\mathrm{SiO}_{2} @$ gold shell and $\mathrm{SiO}_{2} @ A u @ \mathrm{MnO}_{2} \mathrm{NPs}$ exhibited pronounced absorption in the NIR range, revealing that these nanoparticles have the properties which make it an excellent candidate for PTT while combating malignant tumors.

\section{Photothermal properties of the theranostic nanoagent}

The photothermal properties of $\mathrm{SiO}_{2} @$ gold shell were tested with an $808 \mathrm{~nm}$ continuous-wave laser via an IR thermographic system. A significant photothermal effect for the nanomaterials with obvious temperature increase depending on concentration was observed (Fig. S2a †). Meanwhile, cycle heating experiments also verified that $\mathrm{SiO}_{2}$ @gold shell has excellent photothermal stability (Fig. S2b and c $\dagger$ ). The temperature elevation analysis also revealed that the coating of the $\mathrm{MnO}_{2}$ nanosheet exhibited no negative effect on the photothermal properties of the theranostic nanoagent (Fig. S3†). The photothermal heating curves and thermal imaging of the intact theranostic nanoagent $\mathrm{SiO}_{2} @ \mathrm{Au} @ \mathrm{MnO}_{2}-\mathrm{DOX} / \mathrm{Apt}$ illustrated that the temperature of PBS and cell culture medium (DMEM) containing the nanoagent was sharply increased from $25{ }^{\circ} \mathrm{C}$ to $50{ }^{\circ} \mathrm{C}$ while the temperature of pure PBS or DMEM solution only increased by about $\sim 3{ }^{\circ} \mathrm{C}$ under the same laser irradiation conditions (Fig. 2a and $\mathrm{b}$ ). Moreover, the cycle heating experiments proved the photothermal stability of the core-shell structure after five

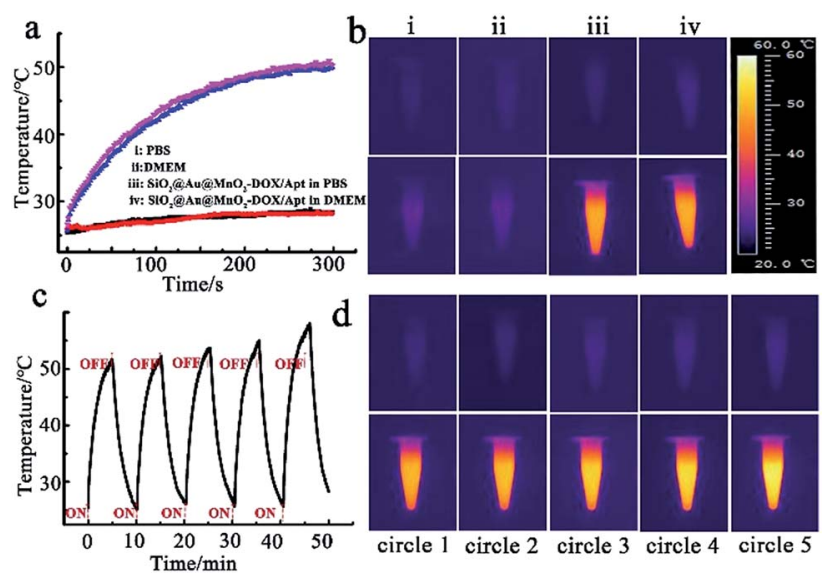

Fig. 2 (a), (b) Temperature-time curves of different solutions under exposure to the $808 \mathrm{~nm}$ laser $\left(2 \mathrm{~W} \mathrm{~cm}^{-2}\right)$ and thermal images of different solutions before (top) and after (bottom) NIR irradiation. (c) The irradiation cycle experiment of $\mathrm{SiO}_{2} \mathrm{aAu} \mathrm{aMnO}_{2}-\mathrm{DOX} / \mathrm{Apt}$, every cycle was composed of 5 min irradiation followed by a 5 min cooling phase. (d) Thermal images of the irradiation cycle experiment. heating and cooling cycles (Fig. 2c and d), proving the proposed nanostructure to be an effective photothermal nanoagent.

\section{Redox-responsive drug release in vitro}

For the purpose of investigating the loading capacity of $\mathrm{MnO}_{2}$ nanosheets and redox activated drug release, a fluorescent chemotherapy drug doxorubicin hydrochloride (DOX) was chosen as a model. Both the zeta potential analysis and UV-vis absorbance measurements were performed to substantiate the loading process. The zeta potential in the loading process changed from $-17.6 \mathrm{mM}$ to $6.73 \mathrm{mV}$, and a strong DOX characteristic absorption peak at $492 \mathrm{~nm}$ appeared (Fig. S4a and $\mathrm{b}^{\dagger}$ ), demonstrating that the drug DOX was successfully loaded on the surface of nanosheets $\mathrm{MnO}_{2}$ via electrostatic interaction. Additionally, the outcomes of UV-vis absorbance measurement further indicated that a DOX loading efficiency ${ }^{40}$ of $89.5 \%$ on $\mathrm{SiO}_{2} @ \mathrm{Au} @ \mathrm{MnO}_{2}$ nanomaterials could be achieved (Fig. S5 $\dagger$ ). GSH, with an elevated intracellular level in the tumor, ${ }^{\mathbf{4 1 , 4 2}}$ served as the redox stimulus. The drug release process was monitored in real time via FI/MRI dual-modal imaging and quantified using UV-vis absorbance measurements. As shown in Fig. 3a, the $\mathrm{SiO}_{2} @ \mathrm{Au} @ \mathrm{MnO}_{2}-\mathrm{DOX} / \mathrm{Apt}$ nanoagent showed good stability and less than $10 \%$ drug leaked from the nanoagent even over a period of $72 \mathrm{~h}$ (black curve). On the contrary, when a low concentration of stimulus GSH was added, the release percent sharply increased to $43 \%$ within $5 \mathrm{~h}$, reached $c a .50 \%$ at $24 \mathrm{~h}$ and then a plateau of release percent was achieved after this reaction point (red curve). Furthermore, a higher concentration stimulus would lead to much more significant release and almost $90 \%$ entrapped drug could be released when the concentration of GSH increases up to $10 \mathrm{mM}$ (blue curve). The outcomes demonstrated that the facilely constructed nanoagent has potential capacities of preventing anticancer drugs from randomly leaking, while triggering drug targeted release by the redox reaction between $\mathrm{MnO}_{2}$ and GSH molecules, which could achieve maximum therapeutic efficacy and minimum side effects.

Subsequently, we performed the fluorescence imaging and MRI imaging of the $\mathrm{SiO}_{2} @ \mathrm{Au} @ \mathrm{MnO}_{2}-\mathrm{DOX} / \mathrm{Apt}$ nanoagent during the GSH-responsive drug release process in vitro. The fluorescence data showed that there was a significant fluorescence activation representing the released drug DOX (Fig. 3b),

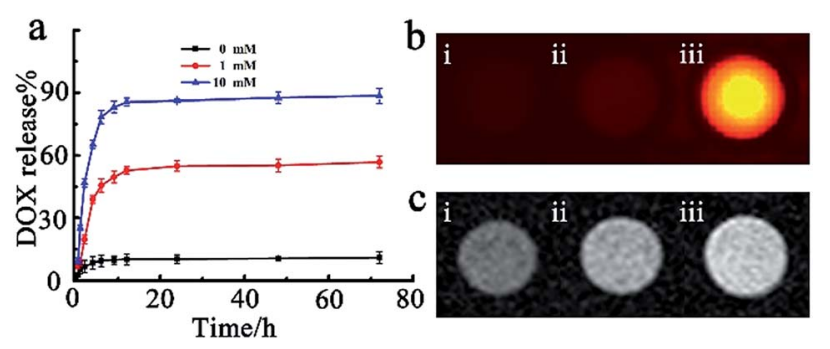

Fig. 3 (a) DOX released from the $\mathrm{SiO}_{2}\left(\mathrm{~A} A u @ \mathrm{MnO}_{2}-\mathrm{DOX} / \mathrm{Apt}\right.$ nanoagent with time at different concentrations of GSH. Corresponding fluorescence imaging (b) and T1-MRI (c) of PBS (i), nanoagent (ii) and nanoagent after incubation with GSH (iii), respectively. 
which was attributed to the quencher $\mathrm{MnO}_{2}$ being reduced by GSH, and decomposed into $\mathrm{Mn}^{2+}$ ions. Free $\mathrm{Mn}^{2+}$ ions, involving a change in the number of unpaired electrons with the $\mathrm{d}^{5}$ electron configuration, have very low absorption band intensities without the quenching ability of manganese oxide. ${ }^{43}$ Meanwhile, the GSH-mediated reduction of $\mathrm{MnO}_{2}$ to paramagnetic $\mathrm{Mn}^{2+}$ ions has led to a significantly strong T1-MRI signal enhancement, demonstrating the capability of the nanoagent to offer T1 contrast in MRI (Fig. 3c). All the results indicated that the entrapped anti-cancer drug release process can result in a concomitant fluorescence signal and T1-MRI signal change, which simultaneously incorporated sensitivity offered by fluorescence imaging with high spatial resolution offered by T1-MRI for the capability of monitoring in real time during in vivo tumor therapy.

\section{Chemotherapy and photothermal therapy in vitro}

Before observing the therapeutic effect of $\mathrm{SiO}_{2} @ \mathrm{Au} @ \mathrm{MnO}_{2}-$ DOX/Apt nanoparticles in cancer cells, we investigated the target efficiency and specificity of the nanoagent with aptamer AS1411 modified on the outer layer $\mathrm{MnO}_{2}$. During the transfection process, target cells-human cervical carcinoma cells (HeLa cells) and normal cells-mouse embryonic fibroblast cells (NIH-3T3 cells $)^{44}$ were incubated with nanomaterials for a period of time, and then washed with PBS solution, and imaged by confocal laser scanning microscopy (CLSM) immediately. An obvious fluorescence signal emitted from DOX, which was loaded in the nanoagent and released via the redox reaction, was observed in HeLa cells (Fig. 4a, i), confirming that a vast amount of nanoparticles could be ingested by the cells. Compared with the malignant cells, almost no fluorescence of DOX could be observed in the normal cells under the same conditions (Fig. 4a, ii). In order to further prove the target specificity of the nanoagent, HeLa cells were incubated with $\mathrm{SiO}_{2} @ \mathrm{Au} @ \mathrm{MnO}_{2}$-DOX without modification with AS1411 under the same conditions. As shown in Fig. 4a, faint fluorescence of DOX was observed in HeLa cells, revealing that few $\mathrm{SiO}_{2} @ \mathrm{Au} @ \mathrm{MnO}_{2}-\mathrm{DOX}$ nanomaterials could be internalized by the cells without aptamer AS1411. These results revealed that by the specific recognition of aptamer AS1411 to nucleolin, which is overexpressed in many malignancies while tightly controlled in normal human tissues, ${ }^{45}$ the nanoagent exclusively entered the target tumor cells, whereas few nonspecific agents were taken up by normal cells, which can achieve maximum therapeutic efficacy and minimum side effects in tumor treatments. The cell viability assay further confirmed that both the $\mathrm{SiO}_{2} @$ @gold shell-Apt and $\mathrm{SiO}_{2} @ \mathrm{Au} @ \mathrm{MnO}_{2}-\mathrm{Apt}$ nanomaterials exhibited excellent biocompatibility, and over $90 \%$ of the HeLa cells survived after $48 \mathrm{~h}$ of incubation with $100 \mu \mathrm{g} \mathrm{mL}$ nanoparticles (Fig. S6†).

To investigate the performance of the smart theranostic nanoagent for chemotherapy in living cells, HeLa cells were firstly incubated with this nanoagent, then exchanged to fresh media and observed by CLSM at the different time points. As illustrated in Fig. 4b, the cell nuclei were stained with Hoechst 33342 , which specifically bound to the minor groove of doublestranded DNA and highlighted the region as blue fluorescence.

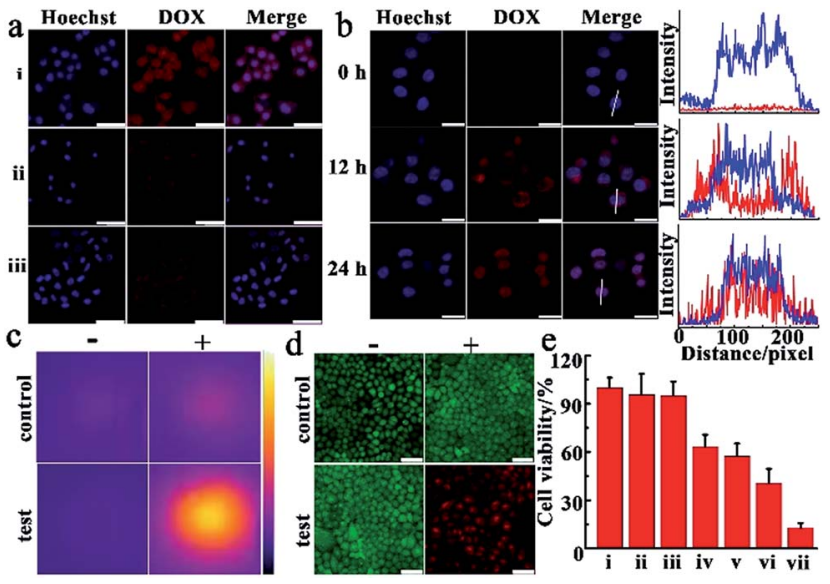

Fig. 4 (a) The CLSM images of HeLa cells and NIH-3T3 cells treated under different conditions, the conditions from top to bottom represent: HeLa cells (i) and $\mathrm{NIH}-3 \mathrm{~T} 3$ cells (ii) incubated with the intact nanoagent $\mathrm{SiO}_{2}\left(\mathrm{aAu} \mathrm{a} \mathrm{MnO}_{2}-\mathrm{DOX} / \mathrm{Apt}\right.$; (iii) HeLa cells incubated with nanomaterials without aptamer modification, $\mathrm{SiO}_{2}\left(\mathrm{Au} a \mathrm{MnO}_{2}-\mathrm{DOX}\right.$. (b) The CLSM images of HeLa cells incubated with the theranostic nanoagent and observed at different time points. The curves represented the distribution of DOX (red lines) and Hoechst 33342 (blue lines) in HeLa cells. (c), (d) The photothermal images (c) and CLSM images (d) of HeLa cells incubated with culture medium as a control group and the theranostic nanoagent as a test group, (-) no NIR irradiation, (+) NIR irradiation. (e) Cell viability of HeLa cells after different treatments. Group (i) control; group (ii) only NIR irradiation; group (iii) $\mathrm{SiO}_{2}$ (agold shell-Apt; group (iv) $\mathrm{SiO}_{2}$ @gold shell-Apt with NIR irradiation (PTT); group (v) pure DOX; group (vi) $\mathrm{SiO}_{2}\left(\mathrm{aAu} a \mathrm{MnO}_{2}-\right.$ DOX/Apt (chemotherapy); group (vii) $\mathrm{SiO}_{2} @ A$ Au@ $\mathrm{MnO}_{2}-\mathrm{DOX} / \mathrm{Apt}$ with NIR irradiation (chemotherapy/PTT). All scale bars are $75 \mu \mathrm{m}$.

With prolonged reaction time it was observed that the gradually increased red fluorescence signal of drug DOX, escaped from the drug delivery system via the redox reaction between the loaded layer $\mathrm{MnO}_{2}$ and internal stimulus GSH. At approximately $24 \mathrm{~h}$, much brighter red fluorescence was observed, showing that the more loaded layer of $\mathrm{MnO}_{2}$ was reduced by GSH, and decomposed into $\mathrm{Mn}^{2+}$ ions and more entrapped drug was released along with time. Meanwhile, red fluorescent signals emitted from released DOX demonstrated a high-level colocalization with the blue fluorescence from cell nuclei (formation of purple spots, Fig. 4b), which was attributed to DOX which has the peculiarity of inserting into the double-helix of DNA to damage DNA, and then tended to accumulate in the cell nuclei with prolonged time.

Next, the photothermal therapy efficacy of the theranostic nanoagent was investigated in malignant cancer cells. In the experiments, HeLa cells were divided into two sets, one as the control set cultured under regular conditions supplied with complete cell culture medium, while the other as the test set incubated with the $\mathrm{SiO}_{2} @ \mathrm{Au} @ \mathrm{MnO}_{2}-\mathrm{DOX} / \mathrm{Apt}$ nanoagent for 3 $\mathrm{h}$, and then washed with fresh cell medium. Following these processes, two sets of cells were irradiated with the $808 \mathrm{~nm}$ laser at $2.0 \mathrm{~W} \mathrm{~cm}{ }^{-2}$ for $5 \mathrm{~min}$, respectively. As presented in Fig. $4 \mathrm{c}$, an obviously bright thermal image was observed, indicating higher temperature of the test set cells than that of the control set. Meanwhile, these results were verified by the staining 
experiments with an AM/PI fluorescent dye, in which AM stained living cells with a green fluorescent signal and PI stained dead cells with a red signal. ${ }^{46}$ As illustrated in Fig. 4d, after being irradiated with an NIR $808 \mathrm{~nm}$ laser just a bright green fluorescence signal was observed in the control set cells (the left image, i). In contrast, in the test set cells only an intense red fluorescence signal representing the dead status was observed. The results implied that the theranostic nanoagent for photothermal therapy can accelerate cancer cell death by absorbing light and converting photon energy into heat to fight cancer cells.

To evaluate the efficacy of combined chemo-photothermal therapy, quantitative analysis of cell viability was carried out after treating the malignant tumor cells under different conditions. As shown in Fig. 4e, cells treated with the laser alone (group ii) exhibited comparable high cell viability to the control (group i), meaning NIR irradiation caused negligible injury to cultured cells. In photothermal treatment, $\mathrm{SiO}_{2} @$ gold shell-Apt subjected to NIR laser irradiation for $5 \mathrm{~min}$ (group iv) showed higher lethality than the group without light irradiation treatment (group iii). In chemotherapy, the theranostic nanoagent treatment (group vi) exhibited a better anticancer effect than free DOX (group v), which was attributed to the targeted delivery of the nanoagent and in situ drug release induced by endogenous GSH. Importantly, the combinational chemo-photothermal therapy group, which was incubated with the nanoagent and irradiated with NIR light (group vii), exhibited the highest cell mortality in contrast to the chemotherapy and PTT alone. All the results about the therapeutic effects proved that the theranostic nanoagent possessed a higher potency to destroy malignant tumor cells and achieved the synergistic effect in combating the tumor, thereby reducing drug dose and mitigating the side effect.

\section{Enhanced antitumor effect of $\mathrm{SiO}_{2} @ A u @ \mathrm{MnO}_{2}-\mathrm{DOX} / \mathrm{Apt} \mathrm{NPs}$ in vivo}

Encouraged by the outstanding synergistic chemotherapy/PTT effect in vitro, the synergetic antitumor capacity of the $\mathrm{SiO}_{2} @$ $\mathrm{Au} @ \mathrm{MnO}_{2}-\mathrm{DOX} / \mathrm{Apt}$ theranostic nanoagent was further validated with a xenograft HeLa tumor-bearing nude mouse model. All the mice treated under different conditions were divided into four groups when the tumor size reached about $100 \mathrm{~mm}^{3}$, group one: injected with PBS (control group), group two: injected with $\mathrm{SiO}_{2} @$ gold shell-Apt with NIR irradiation (PTT), group three: injected with theranostic nanoagent (chemotherapy), group four: injected with nanoagent with NIR irradiation (PTT combined with chemotherapy). The photothermal performance in vivo was verified via an IR thermographic system. The control group and the test group (the fourth group) were irradiated with $808 \mathrm{~nm}$ laser irradiation with a power density of $2.0 \mathrm{~W} \mathrm{~cm}^{-2}$ for $5 \mathrm{~min}$, and then the temperature of the tumor was recorded. As illustrated in Fig. 5a, the temperature of the tumor in the nanoagent injected mice promptly increased up to $\sim 50{ }^{\circ} \mathrm{C}$ after irradiation, which was high enough to kill cancer cells and inhibit the tumor growth while the temperature of tumor in the control group increased slightly up to $35{ }^{\circ} \mathrm{C}$ under the same irradiation conditions. T1-MRI-guided
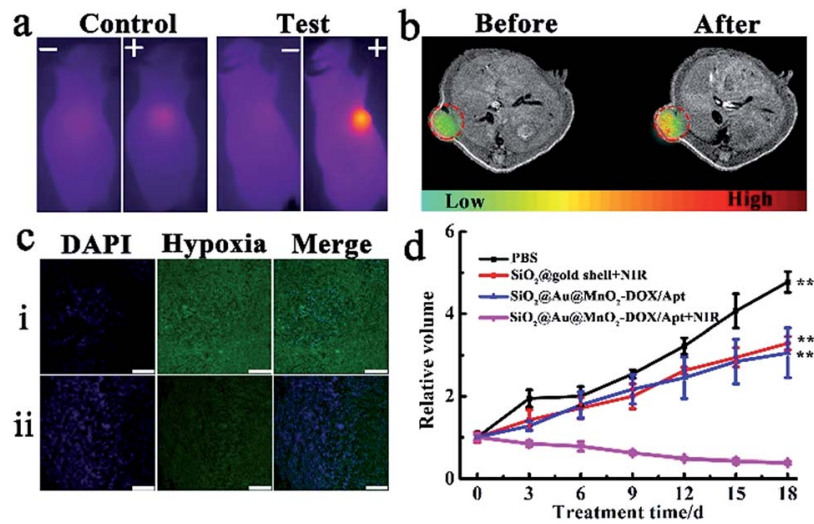

Fig. 5 (a) In vivo photothermal images of the control group with PBS injection and the experimental group with the nanoagent injection for 24 h. (-) no NIR irradiation, (+) NIR irradiation. (b) In vivo T1-weighted MR images of the mice taken before (left) and $24 \mathrm{~h}$ post injection (right) of the nanoagent, the red circles highlight the solid tumor. (c) Micrographs of tumor slices with cell nuclei and hypoxia areas stained with DAPI (blue) and hypoxia-probe (green), control group: injected with PBS (i), test group: injected with $\mathrm{SiO}_{2} \mathrm{QAu}\left(\mathrm{M} \mathrm{MnO}_{2}-\mathrm{DOX} / \mathrm{Apt}\right.$ with NIR irradiation (ii). Scale bar: $75 \mu \mathrm{m}$. (d) The mice weight change curves of different groups of mice after various treatments are indicated (four mice per group).

treatment using the theranostic nanoagent for combating tumors was investigated. Specifically, MRI monitoring of mice before and after the theranostic nanoagent injection was performed using a 1.0-T animal MRI scanner. A clearer enhanced contrast signal in the tumor than that of the control group was observed (Fig. 5b), uncovering that the high targeting and accumulation of the nanoagent in the tumor site and the T1-MR imaging capacity of the internal stimulus $\mathrm{GSH}$ induced chemotherapy.

Subsequently, a hypoxia-probe (pimonidazole) immunofluorescence staining assay was performed to evaluate the capability of the theranostic nanoagent in alleviating the tumor hypoxic microenvironment in vivo. Cell nuclei and hypoxia areas were stained with DAPI (blue) and antipimonidazole antibody (green), respectively. ${ }^{33}$ The control group, treated with PBS solution and without NIR irradiation, displayed intense immunofluorescence with hypoxic characteristics (pimonidazole-stained hypoxia, green). In contrast, for the group treated with the nanoagent and irradiation, an obviously reduced green immunofluorescence signal in tumor slices was observed (Fig. 5c), suggesting that the tumor hypoxic microenvironment was relieved in the experiment group, which was likely attributed to the fact that the nanoagent with photothermal therapy can accelerate the blood flow in the solid tumor, which then resulted in improving the oxygenation level and alleviating hypoxia conditions.

Finally, the therapeutic effects were investigated by monitoring the changes of relative tumor volumes, which was recorded every 3 days during 18 days treatment. Without any treatment, the tumor growth of the PBS injected mice (control group) was extremely quick (Fig. 5d). The second group with PTT treatment alone exhibited a moderate tumor-growth inhibition effect, resulting in a smaller tumor volume compared 


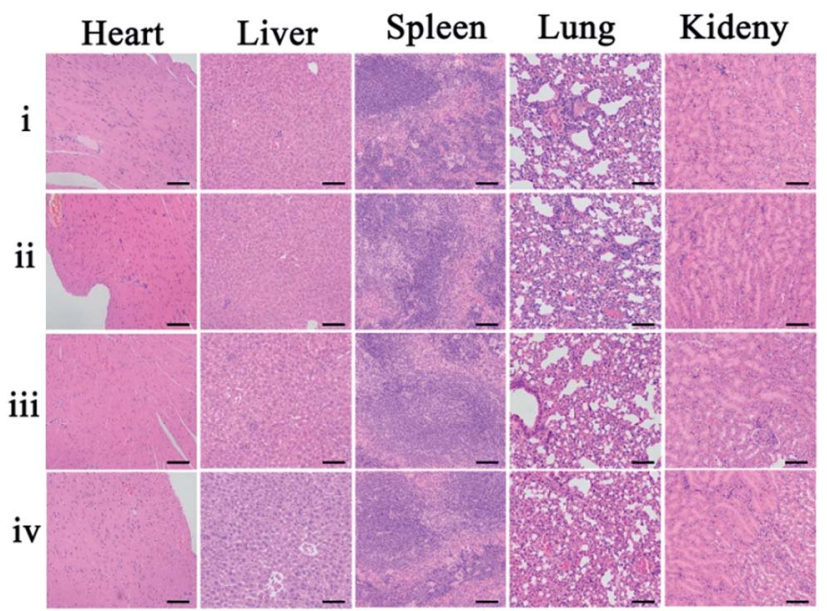

Fig. 6 H\&E stain of major organs from different treatment groups: group one (i) injected with PBS, group two (ii) injected with $\mathrm{SiO}_{2}$ @gold shell-Apt with NIR irradiation, group three (iii) injected with $\mathrm{SiO}_{2} \mathrm{C}$ Au@ $\mathrm{MnO}_{2}-\mathrm{DOX} / \mathrm{Apt}$, and group four (iv) injected with $\mathrm{SiO}_{2} \mathrm{a}$ Au@ $\mathrm{MnO}_{2}-\mathrm{DOX} /$ Apt with NIR irradiation. All scale bars are $50 \mu \mathrm{m}$.

with that of the control group. Meanwhile, the chemotherapy in the third group showed a comparable or slightly better tumorinhibition effect than that of the second group, with only $62.9 \%$ tumor volume of the control group. The most effective result in suppressing tumor growth was achieved in the fourth group under combined chemotherapy/PTT. Tumor volumes of mice in this group gradually decreased and only $7.25 \%$ tumor volume of the control group remained at the end of the treatment. Therefore, a significant synergistic effect of combinational chemo-photothermal therapy in the theranostic nanoagent $\mathrm{SiO}_{2} @ \mathrm{Au} @ \mathrm{MnO}_{2}-\mathrm{DOX} / \mathrm{Apt}$ for combating the solid tumor was validated in vivo.

\section{Toxicity in vivo}

As potential toxicity of the theranostic nanoagent is a very crucial issue in biological studies and therapeutic applications the bodyweight of the mice, as an important parameter to evaluate the systemic toxicity of the material, was measured during the experimental period. No significant difference in the weight changes among these groups was observed within 18 days (Fig. S7 $\dagger$ ). Furthermore, histological analysis of the major organs was carried out to study the cytotoxicity of the theranostic nanoagent in vivo. Images of hematoxylin and eosin (H\&E) stained organ slices, including heart, liver, spleen, lung, and kidney, revealed that no significant tissue damage and adverse effect to these organs could be observed in both the control group and nanoagent treated test groups (Fig. 6). All results revealed that the facilely synthesized core-shell theranostic nanoagent showed excellent biocompatibility and significant promise in practical applications.

\section{Conclusion}

In this study, we successfully developed a multifunctional tumor redox microenvironment-activated theranostic nanoagent based on the core $\mathrm{SiO}_{2}$ coating with a gold shell as the photothermal nanomaterial and $\mathrm{MnO}_{2}$ nanosheets as chemotherapeutic carriers. This nanocomposite achieved high photothermal therapeutic efficacy, overcoming the tumor hypoxic microenvironment and alleviating the side influence of hypoxia on cancer therapy. The nanoagent interacted with GSH to release the drug and $\mathrm{Mn}^{2+}$ simultaneously, enhancing the chemotherapy efficiency. Meanwhile, the synergistic therapy was successfully monitored with thermal, fluorescence imaging and MRI owing to the absorption of NIR light, the decomposed $\mathrm{MnO}_{2}$ and the presence of $\mathrm{Mn}^{2+}$. Modification of aptamer AS1411 on the nanoparticles also significantly enhanced the targeting ability and accumulation in both the cell monolayer in vitro and the solid tumor in vivo. Furthermore, the newly formulated $\mathrm{SiO}_{2} @ \mathrm{Au} @ \mathrm{MnO}_{2}-\mathrm{DOX} / \mathrm{Apt}$ nanoagent achieved excellent tumor growth inhibition effect in the HeLa-tumor bearing nude mouse model, owing to the improvement of the tumor microenvironment and the synergistic effect of combinational chemotherapy/PTT. With excellent biocompatibility and high therapeutic efficacy, the new tumor-targeted theranostic nanoagent has significantl scientific value and opens new avenues for next generation imaging-guided multi-mode cancer treatment.

\section{Experimental}

\section{Synthesis of aminated silica nanoparticles $\left(\mathrm{SiO}_{2}-\mathrm{NH}_{2}\right)$}

$14 \mathrm{~mL}$ of ethanol and $2 \mathrm{~mL}$ of water were mixed for $5 \mathrm{~min}$. Then, $0.6 \mathrm{~mL}$ of TEOS was added to the mixture and stirred for $30 \mathrm{~min}$. Subsequently, ammonium hydroxide $(0.3 \mathrm{~mL})$ was added and the mixture was stirred for $2 \mathrm{~h}$. After that, $\mathrm{SiO}_{2}$ nanoparticles were acquired by centrifugation and rinsed. Then, the above product $\mathrm{SiO}_{2}$ was firstly dispersed in $20 \mathrm{~mL}$ of ethanol, and the aminated reagent APTES $(200 \mu \mathrm{L}, 98 \%)$ was added to the solution. Subsequently, the mixture was heated to reflux and maintained for $12 \mathrm{~h}$ to form aminated silica nanoparticles. Finally, the product was centrifuged and washed with ethanol and water and stored at $4{ }^{\circ} \mathrm{C}$ before use.

\section{Gold seed formation on $\mathrm{SiO}_{2}-\mathrm{NH}_{2}$ nanoparticles $\left(\mathrm{SiO}_{2} @\right.$ gold seed)}

Typically, $0.5 \mathrm{~mL}$ of aminated silica colloid $\left(0.5 \mathrm{mg} \mathrm{mL}^{-1}\right)$ was sonicated and then mixed with $20 \mathrm{~mL}$ of $\mathrm{HAuCl}_{4}(0.25 \mathrm{mM})$. After that, fresh sodium citrate $(0.1 \mathrm{~mL}, 0.2 \mathrm{M})$ and $\mathrm{NaBH}_{4}(1$ $\mathrm{mL}, 0.01 \mathrm{M}$ ) were sequentially added to the mixture at $4{ }^{\circ} \mathrm{C}$ and kept stirring for $6 \mathrm{~min}$ to obtain $\mathrm{SiO}_{2} @$ gold seed. The product was centrifuged and washed with water three times and dispersed in $10 \mathrm{~mL}$ of water at $4{ }^{\circ} \mathrm{C}$ before use.

\section{Gold shell growth on aminated silica nanoparticles ( $\mathrm{SiO}_{2} @$ agold shell)}

$0.5 \mathrm{~mL}$ of the obtained $\mathrm{SiO}_{2} @$ gold seed nanomaterials $(0.2 \mathrm{mg}$ $\left.\mathrm{mL}^{-1}\right)$ was mixed with $\mathrm{HAuCl}_{4}(5 \mathrm{~mL}, 0.25 \mathrm{mM})$. Then, fresh sodium citrate $(0.2 \mathrm{~mL}, 0.2 \mathrm{M})$ and fresh $\mathrm{NH}_{2} \mathrm{OH} \cdot \mathrm{HCl}(39 \mu \mathrm{L}$, $0.04 \mathrm{M}$ ) were sequentially added to the mixture and kept stirring for $10 \mathrm{~min}$. After that, the product named $\mathrm{SiO}_{2} @$ gold shell was 
centrifuged carefully, dispersed in water and kept at $4{ }^{\circ} \mathrm{C}$ for further use.

\section{Synthesis of $\mathrm{SiO}_{2} @ \mathrm{Au} @ \mathrm{MnO}_{2}$ nanomaterials}

The $\mathrm{SiO}_{2} @ \mathrm{Au} @ \mathrm{MnO}_{2}$ nanomaterials were prepared according to a previously reported method ${ }^{23}$ with some modification. $\mathrm{SiO}_{2} @$ gold shell was firstly mixed with 1\% PVP and stirred overnight; then the above mixture $\left(100 \mu \mathrm{L}, 1 \mathrm{mg} \mathrm{mL}^{-1}\right)$ was transferred to a $1.5 \mathrm{~mL}$ centrifuge tube. $200 \mu \mathrm{L}$ of $\mathrm{MES}(0.1 \mathrm{M})$ and $100 \mu \mathrm{L}$ of $\mathrm{KMnO}_{4}(5 \mathrm{mM})$ were added to the centrifuge tube. After sonication for $30 \mathrm{~min}$, the above-mentioned mixture turned brown, and the final product $\left(\mathrm{SiO}_{2} @ \mathrm{Au} @ \mathrm{MnO}_{2}\right)$ was carefully collected by centrifugation, rinsed with water three times and re-dispersed in water for further use.

\section{Drug loading process}

$0.5 \mathrm{~mL}$ of DOX $\left(0.5 \mathrm{mg} \mathrm{mL}{ }^{-1}\right)$ was mixed with $0.5 \mathrm{~mL}$ of $\mathrm{SiO}_{2} @ \mathrm{Au} @ \mathrm{MnO}_{2}\left(1 \mathrm{mg} \mathrm{mL}{ }^{-1}\right)$ and kept stirring in the dark for $24 \mathrm{~h}$. After that, the mixture was centrifuged and washed with water, and then the pellet $\left(\mathrm{SiO}_{2} @ \mathrm{Au} @ \mathrm{MnO}_{2}-\mathrm{DOX}\right)$ was carefully collected, re-dispersed in PBS buffer and stored at $4{ }^{\circ} \mathrm{C}$ before use. The loading efficiency of $\mathrm{SiO}_{2} @ \mathrm{Au} @ \mathrm{MnO}_{2}$ was quantified using UV-vis spectroscopy measurements $(480 \mathrm{~nm})$. The amount of DOX loaded onto the nanocomposite was calculated as follows: the actual amount of the drug loaded in nanoparticles $\left(M_{0}-M\right)$ /the amount of the drug initially added $\left(M_{0}\right) \times$ $100 \%$ ( $M$ : the supernatant amount of DOX, $M_{0}$ : the initial amount of DOX).

\section{Assembling the aptamer on $\mathrm{SiO}_{2} @ \mathrm{Au} @ \mathrm{MnO}_{2}-\mathrm{DOX}$ nanomaterials $\left(\mathrm{SiO}_{2} @ \mathrm{Au} @ \mathrm{MnO}_{2}-\mathrm{DOX} / \mathrm{Apt}\right)$}

In order to assemble the nanostructure with aptamer AS1411, $0.1 \mathrm{~mL}$ of $\mathrm{NH}_{2}$-aptamer $(5 \mathrm{mM})$ was mixed with the nanocomposite $\left(0.2 \mathrm{~mL}, 1 \mathrm{mg} \mathrm{mL}^{-1}\right)$ and kept stirring for $30 \mathrm{~min}$, and then $0.7 \mathrm{~mL}$ of HEPES buffer $(20 \mathrm{mM}, \mathrm{pH} 7.2$, containing $150 \mathrm{mM} \mathrm{NaCl}$ and $2 \mathrm{mM} \mathrm{MgCl}$ ) was added to the above mixture under stirring for $4 \mathrm{~min}$ at room temperature. Finally, the sample was centrifuged and re-dispersed in PBS buffer ( $\mathrm{pH}$ 7.4). Besides, the nanoagent (termed $\mathrm{SiO}_{2} @$ @old shell-Apt) used in PTT alone was modified with the thiolated aptamer and synthesized by the above procedure just without $\mathrm{MnO}_{2}$ coating and the drug loading process.

\section{Cell culture and MTT assay}

HeLa cells were incubated in high-glucose DMEM supplemented with $10 \% \mathrm{FBS}, 100 \mathrm{IU} \mathrm{mL}^{-1}$ penicillin and $100 \mathrm{IU} \mathrm{mL}^{-1}$ streptomycin at $37{ }^{\circ} \mathrm{C}$ in a $5 \% \mathrm{CO}_{2}-95 \%$ air incubator MCO15AC (Sanyo, Tokyo, Japan). HeLa cells were digested and $1 \times$ $10^{4}$ cells were seeded into 96 -well plates for $24 \mathrm{~h}$ at $37^{\circ} \mathrm{C}$. Then, different concentrations of nanomaterials $\left(0 \mu \mathrm{g} \mathrm{mL} \mathrm{m}^{-1}, 20 \mu \mathrm{g}\right.$ $\mathrm{mL}^{-1}, 40 \mu \mathrm{g} \mathrm{mL} L^{-1}, 60 \mu \mathrm{g} \mathrm{mL} L^{-1}, 100 \mu \mathrm{g} \mathrm{mL}{ }^{-1}$ ) were added to wells and incubated with cells for $3 \mathrm{~h}$, respectively. After that, the cells were washed with PBS and incubated in fresh medium for an additional $24 \mathrm{~h}$ and $48 \mathrm{~h}$, respectively. Subsequently, the cell culture medium was discarded and the cells were rinsed three times. Then, $100 \mu \mathrm{L}$ MTT solution $\left(0.5 \mathrm{mg} \mathrm{mL}^{-1}\right.$, PBS) was added to each well and allowed to stand for $4 \mathrm{~h}$ at $37^{\circ} \mathrm{C}$. After that, the MTT solution was discarded and $100 \mu \mathrm{L}$ DMSO was added to each well and shaken for $5 \mathrm{~min}$. Finally, the absorption intensity at $540 \mathrm{~nm}$ of each well was recorded.

\section{Confocal laser scanning microscopy imaging}

HeLa cells were digested and incubated in confocal cell dishes overnight. Then, the cells were incubated with the nanocomposite $\left(60 \mu \mathrm{g} \mathrm{mL}^{-1}\right)$ for $3 \mathrm{~h}$ and then cultured for another 12 $\mathrm{h}$ and $24 \mathrm{~h}$, respectively. After that, the cells were washed three times and then incubated with Hoechst 33342 for 20 min. Finally, confocal laser scanning microscopy (CLSM) images of HeLa cells were acquired after washing with PBS three times.

\section{In vivo antitumor effect analysis}

Nude mice were bought from model animal research center of Nanjing University and the HeLa-tumor bearing nude mice were established by subcutaneous injection of HeLa cells $\left(1 \times 10^{6}\right)$. Then, the HeLa-tumor bearing nude mice were divided into four groups ( $n=4$ each group) with various conditions by tail vein injection: PBS injection as the control group, $\mathrm{SiO}_{2}$ @gold shellApt with NIR irradiation (PTT alone), $\mathrm{SiO}_{2} @ \mathrm{Au} @ \mathrm{MnO}_{2}-\mathrm{DOX} /$ Apt (chemotherapy alone), and $\mathrm{SiO}_{2} @ \mathrm{Au} @ \mathrm{MnO}_{2}-\mathrm{DOX} / \mathrm{Apt}$ with NIR irradiation (chemotherapy/PTT). The interval time of tail vein injection for PBS or nanomaterials was three days. The NIR irradiation was performed $24 \mathrm{~h}$ after injection of nanomaterials with an $808 \mathrm{~nm}$ laser for $5 \mathrm{~min}$ at $2 \mathrm{~W} \mathrm{~cm}^{-2}$. The tumor volumes and body weights of mice were recorded every three days. The tumor volume was calculated according to the equation: volume $=1 / 2(\text { tumor width })^{2} \times$ (tumor length). The photothermal images and MR images were acquired by the related instruments. All animal operations were in accordance with institutional animal use and care regulations approved by the Model Animal Research Center of Nanjing University (MARC).

\section{Immunofluorescence of tumor hypoxia}

The mice were injected with PBS or the nanoagent and then exposed to $808 \mathrm{~nm}$ laser irradiation $\left(2 \mathrm{~W} \mathrm{~cm}^{-2}\right)$ for $5 \mathrm{~min}$. Then, the mice were intravenously injected with pimonidazole hydrochloride $\left(60 \mathrm{mg} \mathrm{kg}^{-1}\right)$. $30 \mathrm{~min}$ later, the mice were sacrificed and the tumors were surgically excised, formalin fixed, then embedded in paraffin. In order to detect pimonidazole, the tissue sections were incubated with mouse FITC-conjugated anti-pimonidazole antibody and rabbit anti-FITC rabbit secondary antibody (dilution $1: 100$ ) according to the kit's instructions. Cell nuclei were stained with DAPI (dilution $1: 5000)$. The images were captured with a confocal microscope (Leica SP5).

\section{Histology analysis}

After 18 days, the tissues (liver, heart, spleen, kidney and lung) were obtained from the sacrificed mice in different experimental groups, and then were fixed in 10\% neutral buffered formalin. After that, these tissues were embedded in paraffin, 
sectioned ( $4 \mu \mathrm{m}$ thick), and stained with hematoxylin and eosin (H\&E). Finally, an optical microscope was used to detect the histological sections.

\section{Statistical analysis}

The statistical analysis was implemented with statistical software SPSS (version 24.0) via Student's $t$ test. Values of ${ }^{*} P<0.05$ were considered to be significant, and values of $* * P<0.001$ were considered to be highly significant.

\section{Conflicts of interest}

There are no conflicts to declare.

\section{Acknowledgements}

This work was supported by the National Natural Science Foundation (Grants 21327902, 21535003, 21605079, 21605072) of China, and the Natural Science Foundation (BK20160637) of Jiangsu Province. This work was also supported by a Project Funded by the Priority Academic Program Development of Jiangsu Higher Education Institutions and the Program B for Outstanding PhD Candidate of Nanjing University (201702B053).

\section{Notes and references}

1 R. A. Gatenby and R. J. Gillies, Nat. Rev. Cancer, 2004, 4, 891. 2 P. A. Ma, H. Xiao, C. Yu, J. Liu, Z. Cheng, H. Song, X. Zhang, C. Li, J. Wang, Z. Gu and J. Lin, Nano Lett., 2017, 17, 928-937. 3 M. Karimi, A. Ghasemi, P. Sahandi Zangabad, R. Rahighi, S. M. Moosavi Basri, H. Mirshekari, M. Amiri, Z. Shafaei Pishabad, A. Aslani, M. Bozorgomid, D. Ghosh, A. Beyzavi, A. Vaseghi, A. R. Aref, L. Haghani, S. Bahrami and M. R. Hamblin, Chem. Soc. Rev., 2016, 45, 1457-1501.

4 G. K. Balendiran, R. Dabur and D. Fraser, Cell Biochem. Funct., 2004, 22, 343-352.

5 S. Thomas, M. A. Harding, S. C. Smith, J. B. Overdevest, M. D. Nitz, H. F. Frierson, S. A. Tomlins, G. Kristiansen and D. Theodorescu, Cancer Res., 2012, 72, 5600-5612.

6 Y. Yamamoto, M. Ibusuki, Y. Okumura, T. Kawasoe, K. Kai, K. Iyama and H. Iwase, Breast Cancer Res. Treat., 2008, 110, 465-475.

7 E. B. Rankin and A. J. Giaccia, Cell Death Differ., 2008, 15, 678-685.

8 M. Schindl, S. F. Schoppmann, H. Samonigg, H. Hausmaninger, W. Kwasny, M. Gnant, R. Jakesz, E. Kubista, P. Birner and G. Oberhuber, Clin. Cancer Res., 2002, 8, 1831-1837.

9 C.-C. Huang, W.-T. Chia, M.-F. Chung, K.-J. Lin, C.-W. Hsiao, C. Jin, W.-H. Lim, C.-C. Chen and H.-W. Sung, J. Am. Chem. Soc., 2016, 138, 5222-5225.

10 X. Cai, W. Gao, M. Ma, M. Wu, L. Zhang, Y. Zheng, H. Chen and J. Shi, Adv. Mater., 2015, 27, 6382-6389.

11 Z. Yu, Y. Ge, Q. Sun, W. Pan, X. Wan, N. Li and B. Tang, Chem. Sci., 2018, 9, 3563-3569.
12 E.-J. Choi, J. Pharm. Invest., 2011, 41, 59-65.

13 J. Zhu, Y. Niu, Y. Li, Y. Gong, H. Shi, Q. Huo, Y. Liu and Q. Xu, J. Mater. Chem. B, 2017, 5, 1339-1352.

14 C. Wang, J. Wang, X. Zhang, S. Yu, D. Wen, Q. Hu, Y. Ye, H. Bomba, X. Hu, Z. Liu, G. Dotti and Z. Gu, Sci. Transl. Med., 2018, 10, eaan3682.

15 J. Wang, Y. Zhang, E. Archibong, F. Ligler and Z. Gu, Adv. Biosyst., 2017, 1, 1700084.

16 D. Peer, J. M. Karp, S. Hong, O. C. Farokhzad, R. Margalit and R. Langer, Nat. Nanotechnol., 2007, 2, 751-760.

17 P. T. Wong and S. K. Choi, Chem. Rev., 2015, 115, 3388-3432.

18 W. Pan, H. Yang, T. Zhang, Y. Li, N. Li and B. Tang, Anal. Chem., 2013, 85, 6930-6935.

19 Y. Li, N. Li, W. Pan, Z. Yu, L. Yang and B. Tang, ACS Appl. Mater. Interfaces, 2017, 9, 2123-2129.

20 Y. Li, Y. Chen, W. Pan, Z. Yu, L. Yang, H. Wang, N. Li and B. Tang, Nanoscale, 2017, 9, 17318-17324.

21 L. Jin, J. Liu, Y. Tang, L. Cao, T. Zhang, Q. Yuan, Y. Wang and H. Zhang, ACS Appl. Mater. Interfaces, 2017, 9, 41648-41658. 22 N. Li, W. Diao, Y. Han, W. Pan, T. Zhang and B. Tang, Chem.Eur. J., 2014, 20, 16488-16491.

23 R. Deng, X. Xie, M. Vendrell, Y.-T. Chang and X. Liu, J. Am. Chem. Soc., 2011, 133, 20168-20171.

24 Z. Ma, X. Jia, J. Bai, Y. Ruan, C. Wang, J. Li, M. Zhang and X. Jiang, Adv. Funct. Mater., 2017, 27, 1604258.

25 G. Yang, L. Xu, Y. Chao, J. Xu, X. Sun, Y. Wu, R. Peng and Z. Liu, Nat. Commun., 2017, 8, 902.

26 Z. Yu, M. Wang, W. Pan, H. Wang, N. Li and B. Tang, Chem. Sci., 2017, 8, 4896-4903.

27 Y. Wang, K. Wang, J. Zhao, X. Liu, J. Bu, X. Yan and R. Huang, J. Am. Chem. Soc., 2013, 135, 4799-4804.

28 H. Liu, D. Chen, L. Li, T. Liu, L. Tan, X. Wu and F. Tang, Angew. Chem., Int. Ed., 2011, 50, 891-895.

29 T. Bao, W. Yin, X. Zheng, X. Zhang, J. Yu, X. Dong, Y. Yong, F. Gao, L. Yan, Z. Gu and Y. Zhao, Biomaterials, 2016, 76, 1124.

30 M. Aioub, S. R. Panikkanvalappi and M. A. El-Sayed, ACS Nano, 2017, 11, 579-586.

31 C. W. Song, A. Shakil, J. L. Osborn and K. Iwata, Int. J. Hyperthermia, 2009, 25, 91-95.

32 P. W. Vaupel and D. K. Kelleher, Int. J. Hyperthermia, 2010, 26, 211-223.

33 G. Song, C. Liang, H. Gong, M. Li, X. Zheng, L. Cheng, K. Yang, X. Jiang and Z. Liu, Adv. Mater., 2015, 27, 61106117.

34 J. Bai, X. Jia, W. Zhen, W. Cheng and X. Jiang, J. Am. Chem. Soc., 2018, 140, 106-109.

35 X.-R. Song, X. Wang, S.-X. Yu, J. Cao, S.-H. Li, J. Li, G. Liu, H.-H. Yang and X. Chen, Adv. Mater., 2015, 27, 3285-3291.

36 X.-L. Li, N. Hao, H.-Y. Chen and J.-J. Xu, Anal. Chem., 2014, 86, 10239-10245.

37 H. Shi, R. Yan, L. Wu, Y. Sun, S. Liu, Z. Zhou, J. He and D. Ye, Acta Biomater., 2018, 72, 256-265.

38 W. Stöber, A. Fink and E. Bohn, J. Colloid Interface Sci., 1968, 26, 62-69.

39 R. Wang, X. Ji, Z. Huang, Y. Xue, D. Wang and W. Yang, J. Phys. Chem. C, 2016, 120, 377-385. 
40 X. Liu, Q. Sun, H. Wang, L. Zhang and J.-Y. Wang, Biomaterials, 2005, 26, 109-115.

41 R. Cheng, F. Feng, F. Meng, C. Deng, J. Feijen and Z. Zhong, J. Controlled Release, 2011, 152, 2-12.

42 Y.-C. Wang, F. Wang, T.-M. Sun and J. Wang, Bioconjugate Chem., 2011, 22, 1939-1945.

43 B. Y. W. Hsu, M. Ng, A. Tan, J. Connell, T. Roberts, M. Lythgoe, Y. Zhang, S. Y. Wong, K. Bhakoo,
A. M. Seifalian, X. Li and J. Wang, Adv. Healthcare Mater., 2016, 5, 721-729.

44 F. Zhou, T. Zheng, E. S. Abdel-Halim, L. Jiang and J.-J. Zhu, J. Mater. Chem. B, 2016, 4, 2887-2894.

45 P. J. Bates, D. A. Laber, D. M. Miller, S. D. Thomas and J. O. Trent, Exp. Mol. Pathol., 2009, 86, 151-164.

46 Q. Chen, C. Liang, C. Wang and Z. Liu, Adv. Mater., 2015, 27, 903-910. 